УДК 373.55

\title{
СПОСОБ РЕАЛИЗАЦИИ СИСТЕМНО-ДЕЯТЕЛЬНОСТНОГО ПОДХОДА ПРИ ИЗУЧЕНИИ ЭЛЕКТИВНОГО КУРСА «ТЕРРИТОРИАЛЬНАЯ ОРГАНИЗАЦИЯ ПРОИЗВОДИТЕЛЬНЫХ СИЛ КАК ФАКТОР РАЗВИТИЯ РЕГИОНА»
}

\author{
Т. М. Позднякова, А. М. Позднякова \\ Приамурский государственный университет имени Шолом-Алейхема, Россия \\ Поступила в редакиию 6 января 2019 г.
}

\begin{abstract}
Аннотация: Статья посвящена оценке эффективности внедрения авторского элективного курса в образовательный процесс средней школы как формы реализации системно-деятельностного подхода в образовании.
\end{abstract}

Ключевые слова: элективный курс, системно-деятельностный подход, информационный проект.

The way to implement the system-activity approach in the study of the elective course «The territorial organization of productive forces as a factor in the development of the region»

\section{T. M. Pozdnyakova, A. M. Pozdnyakova}

\begin{abstract}
The article is devoted to the evaluation of the effectiveness of the author's elective course in the educational process of secondary school as a form of implementation of the system-activity approach in education.
\end{abstract}

Key words: elective course, system-activity approach, information project.

ВВЕДЕНИЕ

В свете активного внедрения Федерального государственного образовательного стандарта (ФГОС) в образовательный процесс средней школы особую актуальность приобретает поиск форм реализации его основных положений. Наибольшего внимания от педагога в данной связи требует построение учебных, а также внеучебных занятий в рамках системно-деятельностного подхода как методологической основы ФГОС. Именно системно-деятельностный подход в образовании призван обеспечить активную учебно-познавательную деятельность, формировать готовность обучающихся к саморазвитию и самообразованию, а также позволяет выстраивать образовательную деятельность с учетом индивидуальных возрастных, психологических и физиологических особенностей обучающихся [1]. Вместе с тем, подбор способов

() Позднякова Т.М., Позднякова А. М., 2019 обеспечения данного подхода является довольно проблематичным.

Одной из эффективных форм реализации системно-деятельностного подхода в образовательном процессе средней школы при изучении дисциплин общественного цикла, с нашей точки зрения, является элективный курс. При этом, элективы, согласно новому ФГОС, должны не только удовлетворять индивидуальные запросы учащихся, расширять и систематизировать знания в выбранной области или виде деятельности, но и обеспечивать формирование общеобразовательной и общекультурной составляющей; развивать познавательные интересы, интеллектуальную и ценностно-смысловую сферы учащихся, навыки самообразования и самопроектирования; совершенствовать имеющийся и предоставлять новый опыт познавательной деятельности учащихся [1]. В этой связи, нами был проведен педагогический эксперимент по разработке и апробации элективного курса «Терри- 
ториальная организация производительных сил как фактор развития региона».

\section{МЕТОДИКА ЭКСПЕРИМЕНТА}

Цель эксперимента: изучение эффективности применения элективного курса как средства реализации системно-деятельностного подхода.

В соответствие с поставленной целью были определены следующие задачи: 1) разработать элективный курс, соответствующий требованиям ФГОС; 2) апробировать данный курс в старших классах средней школы; 3) оценить эффективность курса в соответствии с планируемыми результатами.

Рабочая гипотеза эксперимента заключалась в том, что внедрение элективного курса, составленного в соответствии с требованиями ФГОС, в образовательный процесс средней школы приведет к формированию у учащихся обозначенных выше результатов и станет эффективной формой реализации системно-деятельностного подхода как методологической основы ФГОС нового поколения.

В целевом отношении предлагаемый курс направлен на углубленное изучение историко-географического аспекта социально-экономического развития Новосибирской области - места расположения экспериментальной базы.

Методологические основы разработки курса опираются на «портрет выпускника школы», который характеризуется как: любящий свою Родину и осознающий сопричастность к ее судьбе; умеющий критически мыслить, активно и целенаправленно познавать мир, владеющий основами методов познания окружающего мира; готовый к сотрудничеству, осуществлению проектной и информационно-познавательной деятельности; уважающий мнение других людей, умеющий вести конструктивный диалог, достигать взаимопонимания и успешно взаимодействовать; мотивированный на процесс непрерывного образования и самообразования [1].

Данные характеристики преломляются также в личностных ожидаемых результатах изучения данного курса, среди которых центральное место занимают готовность к саморазвитию и сформированность мотивации к целенаправленной познавательной деятельности.

Метапредметность данного курса достигается сочетанием в его рамках учебных дисциплин обществоведческого характера (география, история, обществознание). В общем виде были определены следующие метапредметные результаты: 1) умение определять целеполагание, задачи и со- ставлять планы деятельности; осуществлять, контролировать и корректировать деятельность; подбирать ресурсы и стратегии, необходимые для достижения поставленных целей и реализации планов деятельности; 2) владение навыками познавательной и учебно-проектной деятельности; способность и готовность к самостоятельному поиску методов решения практических задач; 3) способность и готовность к самостоятельной информационно-познавательной деятельности, владение навыками получения необходимой информации, критически оценивать и интерпретировать информацию, получаемую из различных источников.

Метапредметные результаты, согласно ФГОС, включают освоение межпредметных понятий и формирование универсальных учебных действий (УУД).

К основным межпредметным понятиям, освоенным в процессе изучения курса, относятся: регион, территориальная социально-экономическая система, естественно-природная подсистема, производственная подсистема, производительные силы, территориальная организация общества, социально-экономическое развитие и другие.

Универсальные учебные действия, в свою очередь, подразделяются на три группы: регулятивные, познавательные и коммуникативные. К регулятивным УУД, формируемым в процессе изучения курса, относятся: способность ставить цель, задачи и планировать пути ее достижения; контролировать ход работы по достижению цели, оценивать результат, сопоставлять его с целью и задачами своей деятельности.

Познавательные УУД направлены на повышение предметной компетентности подростков, расширение кругозора в области предметов общественного цикла. Коммуникативные УУд заключаются в приобретении умения работать в группе, учитывать особенности коммуникации партнера, способности к согласованным действиям для достижения общей цели.

Важное значение уделялось способности использования формируемых УУД в познавательной практике, самостоятельности в осуществлении учебной деятельности и организации учебного сотрудничества с педагогами и сверстниками. Данные умения формировались в процессе выбора учащимися тематики учебно-исследовательского направления, самостоятельного планирования и осуществления деятельности для реализации общего проекта, посредством чего проявлялись индивидуальные способности учащихся. 
К основным предметным результатам изучения данного курса можно отнести: 1) овладение представлениями о современной географической науке, ее участии в решении важнейших проблем человечества; 2) применение географического мышления для определения географических аспектов природных и социально-экономических процессов и проблем; 3 ) приобретение системы комплексных социально ориентированных географических знаний о закономерностях размещения населения и хозяйства, динамике и территориальных особенностях процессов, протекающих в географическом пространстве; 4) овладение умениями использовать картографический материал для выявления закономерностей и тенденций, получения нового географического знания о социально-экономических процессах и явлениях; 5) овладение умениями географического анализа и интерпретации разнообразной информации и умениями применять географические знания для объяснения и оценки разнообразных явлений и процессов; 6) овладение умениями применения географического мышления для выделения и оценивания географических факторов, определяющих сущность и динамику важнейших социально-экономических процессов; 7) приобретение комплекса знаний о целостности географического пространства как иерархии взаимосвязанных природно-общественных территориальных систем; 8) овладение умениями выполнять учебные проекты [1].

Предметные результаты так же включают освоение новых для учащихся видов деятельности по получению новых знаний, их преобразованию и применению в учебно-проектных целях. Формирование научного типа мышления в рамках нашего курса выражается в том, что учащиеся знакомятся с основами подготовки информационного проекта, затем отбирают информацию по опреде- ленной тематике и в процессе ее анализа готовят групповой информационный проект.

Владение научной терминологией, ключевыми понятиями, методами и приемами ведения проектной деятельности также являются предметными результатами элективного курса. Однако важнейшим предметным результатом, с нашей точки зрения, явилось формирование целостного представления об изучаемом объекте (территории Новосибирской области) путем освоения и систематизации научных знаний и способов действий на метапредметной основе.

Исходя из требований, предъявляемых ФГОС к предметной области «Общественные науки», были сформулированы основные задачи изучения данного курса: 1) сформировать мировоззренческий, ценностно-смысловой взгляд учащихся; 2) сформировать навыки критического мышления, анализа и синтеза, умения оценивать и сопоставлять методы исследования, характерные для общественных наук; 3) сформировать целостное восприятие всего спектра природных, экономических и социальных реалий; 4) сформировать умения обобщать, анализировать и оценивать информацию с целью проверки гипотез и интерпретации данных различных источников [1].

Содержательный аспект рабочей программы элективного курса, направленный на достижение планируемых результатов, представлен в таблицах 1 и 2.

Разработанный элективный курс включает три основных раздела, каждый из которых, по своей сути, является этапом к подготовке итогового группового информационного проекта.

Первый этап - вводный. В процессе его изучения посредством фронтальных бесед учитель знакомит участников курса со сложившимися подходами к территориальной организации производи-

Структура курса «Территориальная организация производительных сил (далее - ТО ПС) как фактор развития региона»

\begin{tabular}{|c|l|c|c|}
\hline $\begin{array}{c}\text { № } \\
\text { П/п }\end{array}$ & \multicolumn{1}{|c|}{ Раздел } & $\begin{array}{c}\text { Форма организации } \\
\text { деятельности }\end{array}$ & $\begin{array}{c}\text { Основной вид } \\
\text { деятельности }\end{array}$ \\
\hline 1 & $\begin{array}{l}\text { Теоретические аспекты } \\
\text { исследования ТО ПС }\end{array}$ & Фронтальная работа & Беседа \\
\hline 2 & $\begin{array}{l}\text { ТО ПС Новосибирской } \\
\text { области: историко- } \\
\text { географический аспект }\end{array}$ & Индивидуальная работа & $\begin{array}{c}\text { Информационный } \\
\text { проект }\end{array}$ \\
\cline { 1 - 2 } 3 & ТО ПС и развитие региона & Групповая работа & \multicolumn{2}{|c}{} \\
\hline
\end{tabular}


Тематическое планирование курса (17 часов)

\begin{tabular}{|c|c|c|}
\hline $\begin{array}{l}\text { № } \\
\Pi / \Pi\end{array}$ & Тема занятия & $\begin{array}{l}\text { Количество } \\
\text { часов }\end{array}$ \\
\hline 1 & $\begin{array}{l}\text { Теоретические аспекты исследования ТО ПС } \\
\text { Проблема изучения ТО ПС в экономической географии }\end{array}$ & 1 \\
\hline 2 & Подходы и методы исследования производительных сил & 2 \\
\hline 3 & Регион как пространственная основа ТО ПС & 1 \\
\hline 4 & $\begin{array}{l}\text { ТО ПС Новосибирской области: историко-географический } \\
\text { аспект } \\
\text { Этапы анализа ТО ПС объекта исследования }\end{array}$ & 1 \\
\hline 5 & Естественно-природная подсистема региона & \multirow{7}{*}{8} \\
\hline 6 & \multirow{5}{*}{$\begin{array}{l}\text { Производственная подсистема региона: } \\
\text { «Дорусское» освоение } \\
\text { Начало русского освоения } \\
\text { ТО ПС НСО в советский период } \\
\text { ТО ПС НСО в постсоветский период }\end{array}$} & \\
\hline 7 & & \\
\hline 8 & & \\
\hline 9 & & \\
\hline 10 & & \\
\hline 11 & ТО ПС НСО сегодня & \\
\hline 12 & $\begin{array}{l}\text { Круглый стол: «ТО ПС НСО как фактор развития } \\
\text { региона». Подведение итогов курса }\end{array}$ & 4 \\
\hline
\end{tabular}

тельных сил, современными взглядами на регионы как территориальные социально-экономические системы. На данном этапе также происходит постановка цели, задач курса, выявляются способы их решения.

В процессе работы над вторым, рабочим, этапом, каждый учащийся выбирает одно из индивидуальных заданий для сбора информации. Их тематика базируется на полученных теоретических знаниях и соответствует темам второго раздела. Учителю в это время отводится роль консультанта, ход выполнения задания планируется учащимся самостоятельно и оформляется в виде реферата по выбранной теме.

На заключительном этапе происходит обмен наработанными материалами в форме защиты рефератов учащимися. Затем, в соответствии с целеполаганием, определенным на первом этапе, в процессе заседания круглого стола, учащиеся делают выводы о значении территориальной организации производительных сил на уровень регионального развития на примере Новосибирской области. Итогом работы является выработка предложений по оптимизации территориальной организации производительных сил на современном этапе развития региона. Материальным выражением информационного проекта будет являться постер «Актуальные направления Территориальной организации производительных сил как фактор развития Новосибирской области».

\section{ОБСУЖДЕНИЕ РЕЗУЛЬТАТОВ}

Педагогический эксперимент по выявлению эффективности внедрения элективного курса в образовательный процесс проводился на базе МОУ СОШ №1 муниципального района Новосибирской области в течение 2017-2018 учебного года. В нем принимали участие 8 школьников 11 класса, пожелавшие изучать предложенный курс.

Оценка достижения планируемых результатов была проведена по следующим позициям: 1) диагностика сформированности ценностно-смысловой сферы учащихся; 2) качество выполнения индивидуального задания; 3) участие в подготовке информационного проекта.

Диагностика ценностных ориентаций подростков по методике В.Ф. Сопова и Л.В. Карпушиной проводилась дважды - в сентябре 2017 года и в июне 2018 года [1]. Диагностические категории данной методики представлены качественными показателями по пяти диагностическим шкалам.

Шкала «Познание как ценность» направлена на выявление у учащихся потребности в познании и эмоционального восприятия процесса познания (увлеченность учебой, стремление к получению представлений об основных законах природы и общества, творческий подход к выполнению учебных задач). Определяется степень выраженности стремления к приобретению знаний об окружающем мире, а также готовность прилагать опреде- 
Способ реализации системно-деятельностного подхода при изучении элективного курса «Территориальная организащия производительных сил как фактор развития региона»

Таблица 3

Определение уровней ценностных ориентации

\begin{tabular}{|l|c|c|c|}
\hline \multirow{2}{*}{\multicolumn{1}{|c|}{ Показатели ценностных ориентаций }} & \multicolumn{3}{|c|}{ Уровень ценностных ориентаций } \\
\cline { 2 - 4 } & 1, баллы & 2, баллы & 3 , баллы \\
\hline I. Познание & $8-10$ & $5-7$ & $0-4$ \\
\hline II. Я - ценность & $8-10$ & $4-7$ & $0-3$ \\
\hline III. Другой - ценность & $8-10$ & $4-7$ & $0-3$ \\
\hline IV. Общественно полезная деятельность & $9-10$ & $4-8$ & $0-3$ \\
\hline V. Ответственность & $9-10$ & $6-8$ & $0-5$ \\
\hline
\end{tabular}

Таблииа 4

Динамика развития ценностей личности от 10 к 11 классу

\begin{tabular}{|c|c|c|c|c|c|c|c|c|c|c|c|c|c|c|c|c|}
\hline \multirow{3}{*}{ 量 } & \multirow{3}{*}{ 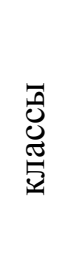 } & \multicolumn{15}{|c|}{ Ценностные ориентации и уровни их развития (количествово человек) } \\
\hline & & \multicolumn{3}{|c|}{ Познание } & \multicolumn{3}{|c|}{ Я - ценность } & \multicolumn{3}{|c|}{$\begin{array}{l}\text { Другой - } \\
\text { ценность }\end{array}$} & \multicolumn{3}{|c|}{$\begin{array}{c}\text { Общественно- } \\
\text { полезная } \\
\text { деятельность }\end{array}$} & \multicolumn{3}{|c|}{$\begin{array}{c}\text { Ответствен- } \\
\text { ность }\end{array}$} \\
\hline & & 1 & 2 & 3 & 1 & 2 & 3 & 1 & 2 & 3 & 1 & 2 & 3 & 1 & 2 & 3 \\
\hline 홍 & 10 & 3 & 3 & 2 & 4 & 2 & 2 & 2 & 3 & 3 & 4 & 2 & 2 & 3 & 3 & 2 \\
\hline$\stackrel{\infty}{\stackrel{\sim}{\circ}}$ & 11 & 6 & 2 & 0 & 5 & 2 & 1 & 5 & 2 & 1 & 7 & 1 & 0 & 6 & 1 & 1 \\
\hline
\end{tabular}

ленные усилия в познавательной деятельности и в процессе освоения новых видов деятельности.

Шкала «Я - ценность» ориентирована на выявление отношения учащегося к себе, определение характера образа «Я» посредством наличия уверенности в собственных силах, веры в свои успехи, в открытости и искренности при общении с другими людьми, в знании собственных позитивных качеств и способностей, умении опираться на них. Данная шкала позволяет обратить внимание на то, формируются ли у подростков такие важные личностные характеристики, как стремление к самопознанию, осознание собственных чувств и поступков, интерес к себе как к личности, способность принимать себя таким, как есть, ценить свои достоинства, осознавать собственную значимость и неповторимость.

Шкала «Другой - ценность» указывает на установки, которые формируются у подростков по отношению к другим людям, насколько они готовы воспринимать другого человека как личность, стремятся ли проявлять доброжелательность, уважительность, доверие, веру в личностный потенциал другого. Этот показатель определяет умение учащегося конструктивно выстраивать межличностные отношения.
Шкала «Общественно полезная деятельность» показывает степень осознания учащимся важности общественно полезной деятельности как личностной ценности. Показателями развития данной ценности являются: ориентация на общественную значимость выполняемого дела; интерес к участию в общественно полезном труде; поддержка активности и поощрение инициативности окружающих; творческое отношение и нацеленность на полезность своей деятельности для других. Таким образом, определяется степень выраженности сознательного отношения к общественно полезной деятельности, уровень осознания сущности человека как существа общественного.

Шкала «Ответственность как ценность» выявляет степень ответственности учащегося за события, происходящие в его жизни. Определяется потребность в обосновании совершаемых действий, стремлении анализировать свои поступки, руководствуется ли человек при принятии решений принципами, основанными на чувстве долга, добросовестно ли относится к выполняемым делам. Данная шкала крайне важна в плане формирования социально-адаптивной личности.

Содержательный блок для каждой из шкал включает 10 вопросов, за ответы на которые, в со- 
Критерии оценки подготовки индивидуального задания для информационного проекта

\begin{tabular}{|c|c|c|c|c|c|c|c|c|}
\hline \multirow{2}{*}{ 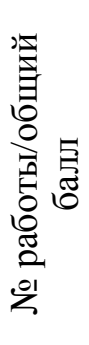 } & \multirow{2}{*}{ 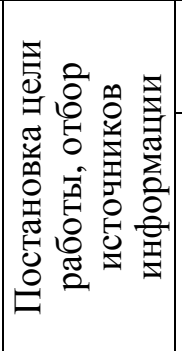 } & \multicolumn{4}{|c|}{ Содержание и качество работы } & \multirow{2}{*}{ 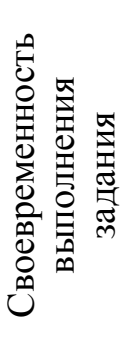 } & \multirow{2}{*}{ 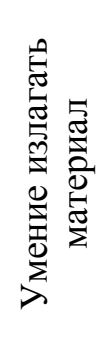 } & \multirow{2}{*}{ 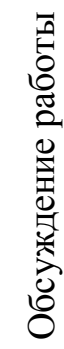 } \\
\hline & & $\begin{array}{c}\text { соответствие } \\
\text { цели и } \\
\text { задачам }\end{array}$ & $\begin{array}{c}\text { логичность } \\
\text { изложения } \\
\text { материала }\end{array}$ & $\begin{array}{c}\text { критический } \\
\text { подход к } \\
\text { анализируемой } \\
\text { информации }\end{array}$ & $\begin{array}{l}\text { грамот- } \\
\text { ность, } \\
\text { оформ- } \\
\text { ление }\end{array}$ & & & \\
\hline $1 / 30$ & 4 & 4 & 4 & 4 & 4 & 3 & 4 & 3 \\
\hline $2 / 29$ & 4 & 3 & 4 & 3 & 4 & 4 & 3 & 4 \\
\hline $3 / 34$ & 5 & 5 & 4 & 4 & 4 & 4 & 4 & 4 \\
\hline $4 / 30$ & 4 & 4 & 3 & 4 & 4 & 4 & 4 & 3 \\
\hline $5 / 32$ & 4 & 4 & 4 & 4 & 4 & 4 & 4 & 4 \\
\hline $6 / 30$ & 4 & 4 & 4 & 3 & 4 & 4 & 3 & 4 \\
\hline $7 / 32$ & 5 & 5 & 4 & 4 & 5 & 4 & 5 & 5 \\
\hline $8 / 33$ & 5 & 5 & 5 & 4 & 5 & 5 & 4 & 4 \\
\hline
\end{tabular}

ответствие с ключом, начисляется 1 балл. Для интерпретации результатов подсчитывается сумма баллов по каждому содержательному блоку, то есть определяется присутствие каждой названной ценности. Для изучения наличия тех или иных ценностных ориентаций рассматривается три уровня проявления названных ценностей: 1 - высокий; 2 - средний; 3 - низкий (таблица 3).

Результаты диагностики представлены в таблице 4.

Данные таблицы 4 показывают положительную динамику развития ценностно-смысловой сферы учащихся в течение года по каждой из шкал. Это выражается в росте количества учащихся, достигающих 1 (высокого) и 2 (среднего) уровней развития ценностных ориентаций. В частности, наблюдается тенденция значительного увеличения количества учащихся с высоким уровнем ценностных ориентации за счет перехода с низкого и среднего, что характерно для таких шкал как «Познание», «Другой - ценность», а также «Ответственность», «Общественно полезная деятельность», где рост учащихся с высоким уровнем сформированности данных ценностей составил 50 \% и более. Улучшились также показатели по шкале «Я ценность», что позволяет сделать вывод о достижении такого результата как сформированность ценностно-смысловой сферы учащихся.

Такие результаты как сформированность навыков критического мышления, целостного восприятия спектра природных и социально- экономических реалий, умений обобщать, анализировать и оценивать информацию различных источников диагностируются посредством качества выполнения индивидуального задания и степенью участия в создании группового проекта как формы реализации системно-деятельностного подхода. Таким образом, выделенные критерии отражают сформированность предметных знаний и способов действий, а также познавательных, регулятивных и коммуникативных УУД (таблица 5).

За каждый критерий начисляется определенное количество баллов по пятибалльной системе (максимум - 40 баллов). Затем все баллы суммируются, определяется качество выполнения задания: до 20 баллов (до 50\%) - низкое, 20-30 баллов (50-75\%) - среднее, 31-40 баллов (76-100\%) - высокое.

Поскольку данный курс использовался в образовательной практике впервые, его результативность также определим в сравнении с уровнем подготовки проектов, представленных данными учащимися в 2017 учебном году (шкала качества соответствует актуальной, таблица 6).

Данные таблицы показывают, что, по сравнению с предыдущим учебным годом, количество учащихся, показавших высокое качество выполнения работы, выросло на $25 \%$. На столько же сократилось количество учащихся, имеющих низкое качество итоговой проектной деятельности.

Возможным следствием реализации данного элективного курса является также более высокий показатель выбора учащимися дисциплин общественного цикла для сдачи Единого государственного экзамена в 11 классе по сравнению с 9 классом. Так, двое учащихся выбрали историю и шес- 
Способ реализации системно-деятельностного подхода при изучении элективного курса «Территориальная организащия производительных сил как фактор развития региона»

Таблица 6

Динамика результативности подготовки информационных проектов

\begin{tabular}{|c|c|c|c|}
\hline \multirow{2}{*}{$\begin{array}{c}\text { Учебный год } \\
\text { (класс) }\end{array}$} & \multicolumn{3}{|c|}{ Качество выполнения работы (\% учащихся) } \\
\cline { 2 - 4 } & высокое & среднее & низкое \\
\hline $\begin{array}{c}2016-2017 \\
(10 \text { класс) }\end{array}$ & $25 \%$ & $50 \%$ & $25 \%$ \\
\hline $\begin{array}{c}2017-2018 \\
(11 \text { класс) }\end{array}$ & $50 \%$ & $50 \%$ & $0 \%$ \\
\hline
\end{tabular}

теро - географию, в то время как в 9 классе географию выбрали двое из них, а история не выбиралась вообще; обществознание сдавалось всеми учащимися и в 9 , и в 11 классе.

\section{ЗАКЛЮЧЕНИЕ}

Таким образом, анализ апробации элективного курса «Территориальная организация производительных сил как фактор развития региона» на основе системно-деятельностного подхода отражает качественный рост результатов образовательного процесса в средней школе. Основными из них стали: развитие мировоззрения и ценностно-смысловой сферы, комплексность и критичность мышления, большая заинтересованность к изучению дисциплин общественного цикла, а также готовность к саморазвитию, самообразованию и сотрудничеству для достижения общей цели.

Позднякова Татьяна Михайловна

кандидат географических наук, доцент кафедры географии, экологии и природоохранного права факультета экономики, экологии и права Приамурского государственного университета имени Шолом-Алейхема, г. Биробиджан, E-mail: russland-54@ mail.ru

Позднякова Анна Михайловна

магистрант 2 курса факультета экономики, экологии и права Приамурского государственного университета имени Шолом-Алейхема, г. Биробиджан, E-mail: iatsso@mail.ru
Полученные данные подтверждают рабочую гипотезу проведенного педагогического эксперимента, позволяют сделать вывод об эффективности курса в целом, а также о возможности реализации посредством его внедрения в образовательный процесс средней школы системно-деятельностного подхода как методологической основы ФГОС нового поколения.

\section{СПИСОК ЛИТЕРАТУРЫ}

1. Изучение ценностных ориентаций подростков : сборник диагностических методик / сост. Н. Д. Елдынова. - Валуйки : ГБОУ СПО Валуйский колледж, 2013. $-51 \mathrm{c}$.

\section{REFERENCES}

1. Izuchenie tsennostnykh orientatsiy podrostkov : sbornik diagnosticheskikh metodik / sost. N. D. Eldynova. - Valuyki : GBOU SPO Valuyskiy kolledzh, 2013. - 51 s.

Pozdnyakova Tat'yana Michaylovna

Candidate of Geographical Sciences, Associate Professor of the Departament of Geography, ecology and environmental law, the Faculty of Economics, ecology and law, Sholom-Aleichem Priamursky State University, Birobidzhan, E-mail: russland-54@mail.ru

Pozdnyakova Anna Michaylovna

Master student 2nd year the Faculty of Economics, Ecology and Law, Sholom-Aleichem Priamursky State University, Birobidzhan, E-mail: iatsso@ mail.ru 